(2) Open Access Full Text Article

REVIEW

\title{
Antidepressant-associated sexual dysfunction: impact, effects, and treatment
}

This article was published in the following Dove Press journal:

Drug, Healthcare and Patient Safety

8 September 2010

Number of times this article has been viewed

\author{
Agnes Higgins \\ Michael Nash \\ Aileen M Lynch \\ School of Nursing and Midwifery \\ Studies, Trinity College Dublin, \\ Dublin, Ireland
}

\begin{abstract}
Sexual dysfunction is a common side effect of antidepressants and can have significant impact on the person's quality of life, relationships, mental health, and recovery. The reported incidence of sexual dysfunction associated with antidepressant medication varies considerably between studies, making it difficult to estimate the exact incidence or prevalence. The sexual problems reported range from decreased sexual desire, decreased sexual excitement, diminished or delayed orgasm, to erection or delayed ejaculation problems. There are a number of case reports of sexual side effects, such as priapism, painful ejaculation, penile anesthesia, loss of sensation in the vagina and nipples, persistent genital arousal and nonpuerperal lactation in women. The focus of this article is to explore the incidence, pathophysiology, and treatment of antidepressant iatrogenic sexual dysfunction.
\end{abstract}

Keywords: depression, antidepressant, iatrogenic sexual dysfunction, SSRI, SNRI

\section{Introduction}

Sexual dysfunction is a common side effect of antidepressants, particularly of selective serotonin reuptake inhibitor (SSRIs) and serotonin norepinephrine reuptake inhibitor (SNRIs) medications. Sexual dysfunction can have significant impact on the person's quality of life, quality of relationships, self esteem, and recovery and can lead to noncompliance with antidepressant treatment with a potential for relapse of symptoms. ${ }^{1}$ Despite this and the frequency of researchers reporting antidepressant-associated sexual dysfunction within the literature, it continues to be underreported or underemphasized on client information leaflets, package inserts, ${ }^{2}$ and verbal information given to clients by practitioners. ${ }^{3}$

During the 60 s and 70s, reports of antidepressant-associated sexual dysfunction were rare; ${ }^{4}$ possibly due to underreporting, lack of discussion and assessment, and an assumption that people with mental health problems were asexual and lacked any sexual desire. ${ }^{5}$ The increased recognition of drug induced sexual dysfunction is multifaceted: including a greater willingness on behalf of researchers to include questions on sexual function and sexual desire; use of antidepressants for other conditions in a population that does not have a mental health problem; greater focus on service users views and quality of life issues; and as Balon ${ }^{4}$ suggests, marketing competition among pharmaceutical companies. The focus of this article is to explore the incidence, pathophysiology, and treatment of antidepressant-associated sexual dysfunction.
Correspondence: Agnes Higgins School of Nursing and Midwifery Studies, Trinity College Dublin, 24, D’Olier St, Dublin 2, Ireland Tel +35318963703

Fax +353 I896 300।

Email ahiggins@tcd.ie 


\section{Incidence of antidepressant- associated sexual dysfunction}

Pharmacotherapy of depression involves the use of antidepressants which modulate central neurotransmitter levels, namely serotonin, norepinephrine, and dopamine. The main classes of antidepressants are the tricyclic antidepressants (TCAs), SSRIs, SNRIs, monoamine oxidase inhibitors (MAOIs), and the atypical antidepressants.

Treatment-emergent sexual dysfunction has been reported with virtually all of the antidepressants. The reported incidence of sexual dysfunction associated with antidepressant medication varies considerably between studies, making it difficult to estimate the exact incidents or prevalence. Rothschild ${ }^{6}$ in a review of research studies on antidepressants and sexual function concluded that $40 \%$ of people taking antidepressants will develop some form of sexual dysfunction. Studies estimate that the incidence varies from $30 \%$ of people treated with imipramine ${ }^{7}$ to $25 \%-73 \%$ of people treated with an SSRI ${ }^{8-11}$ with $93 \%$ of the men and women treated with clomipramine in one study complaining of total or partial anorgasmia. ${ }^{12}$ Montjo-Gonzales et $\mathrm{al}^{10}$ reported an overall incidence of $58 \%$ in an unblinded study involving 344 clients who had a history of normal sexual function before SSRI treatments. The frequency of sexual side effects was highest for paroxetine (65\%), fluvoxamine (59\%), sertaline (56\%) and fluoxetine (54\%). In a multicenter, prospective, Spanish study involving 1022 people, Montejo et a ${ }^{12}$ reported a $59.1 \%$ overall incidence of sexual dysfunction when all antidepressants were considered as a whole. The differences between drugs are summarized in Table 1 and were as follows: incidence of sexual dysfunction with SSRIs and venlafaxine (an SNRI) were high ranging between $58 \%$ and $70 \%$ - fluoxetine $(57.7 \%)$, sertaline (62.9\%), fluvoxamine $(62.3 \%)$, venlafaxine $(67 \%)$, paroxetine $(70.7 \%)$, and citalopram (72.7\%). This compared with a much lower incidence for the newer 5-HT2 blockers (8\% nefazodone and 24\% mirtazapine). Moclobemide, a reversible MAOI, (3.9\%) resulted in the lowest incidence of sexual dysfunction. When differences between men and women were compared, men reported a slightly higher frequency of sexual dysfunction than women (62\% and $60 \%)$. Clayton et al, ${ }^{13}$ in an adult outpatient population (4534 women and $1763 \mathrm{men}$ ) receiving antidepressant monotherapy, reported rates of sexual dysfunction as follows: mirtazapine and venlafaxine extended release were associated with higher rates $(36 \%-43 \%)$, followed by nefazodone (28\%), bupropion SR (25\%) and bupropion IR (22\%).
Modell et al ${ }^{11}$ investigated through self-reported anonymous questionnaires, the sexual side effects of bupropion and the SSRIs (fluoxetine, paroxetine, and sertraline) among 107 outpatients. Overall, 73\% of the SSRI-treated clients reported adverse sexual side effects; in contrast, to $14 \%$ of clients treated with bupropion. The three SSRIs, to an equal degree, significantly decreased libido, arousal, duration of orgasm, and intensity of orgasm below levels experienced premorbidly. In comparison, bupropion-treated clients reported significant increases in libido, level of arousal, intensity of orgasm, and duration of orgasm beyond levels experienced premorbidly. Consequently, the authors concluded that adverse sexual effects appear to be the rule rather than the exception with SSRIs. In a similar study, Kennedy et $\mathrm{al}^{8}$ compared the effects of moclobemide, paroxetine, sertraline, and venlafaxine on drive/desire and arousal/orgasm. Similar to other studies, rates of sexual dysfunction were higher for sertraline, paroxetine, and venlafaxine, when compared with moclobemide. Compared with women, men experienced a significantly greater level of impairment in drive/desire, whereas no difference was reported in levels of arousal/orgasm. No difference was found across the four antidepressants in men, whereas rates of sexual dysfunction were higher in women who were prescribed with sertraline and paroxetine.

A number of double blind comparative studies without placebo control have also been conducted. Kavoussi et al ${ }^{14}$ in a randomized double-blind study, of 248 people with moderate to severe depression, compared sustained-release bupropion and sertraline on sexual function. They reported that orgasmic dysfunction was significantly $(P<0.001)$ more common in the sertraline-treated group. During the 16-week trial, $61 \%$ men and $41 \%$ of women treated with sertaline reported orgasmic dysfunction, compared with $10 \%$ men and $7 \%$ of women in the bupropion. Segraves et a ${ }^{15}$ also compared the effects of sustained-release bupropion and sertraline on sexual function, in 240 people with moderate to severe depression. They reported similar results, with a significantly greater percentage of sertraline-treated clients ( $63 \%$ and $41 \%$ of men and women, respectively) developed sexual dysfunction compared with bupropion SR-treated clients ( $15 \%$ and $7 \%$ of men and women, respectively). Sexual dysfunction was noted as early as day 7 in sertralinetreated clients and persisted until the end of the 16-week treatment phase. Four clients, all of whom were treated with sertraline, discontinued from the study prematurely because of sexual dysfunction. Feiger et a $1^{16}$ compared the effects of nefazodone with sertraline in 160 clients with major mood disorder. Findings suggested that for men, overall satisfac- 


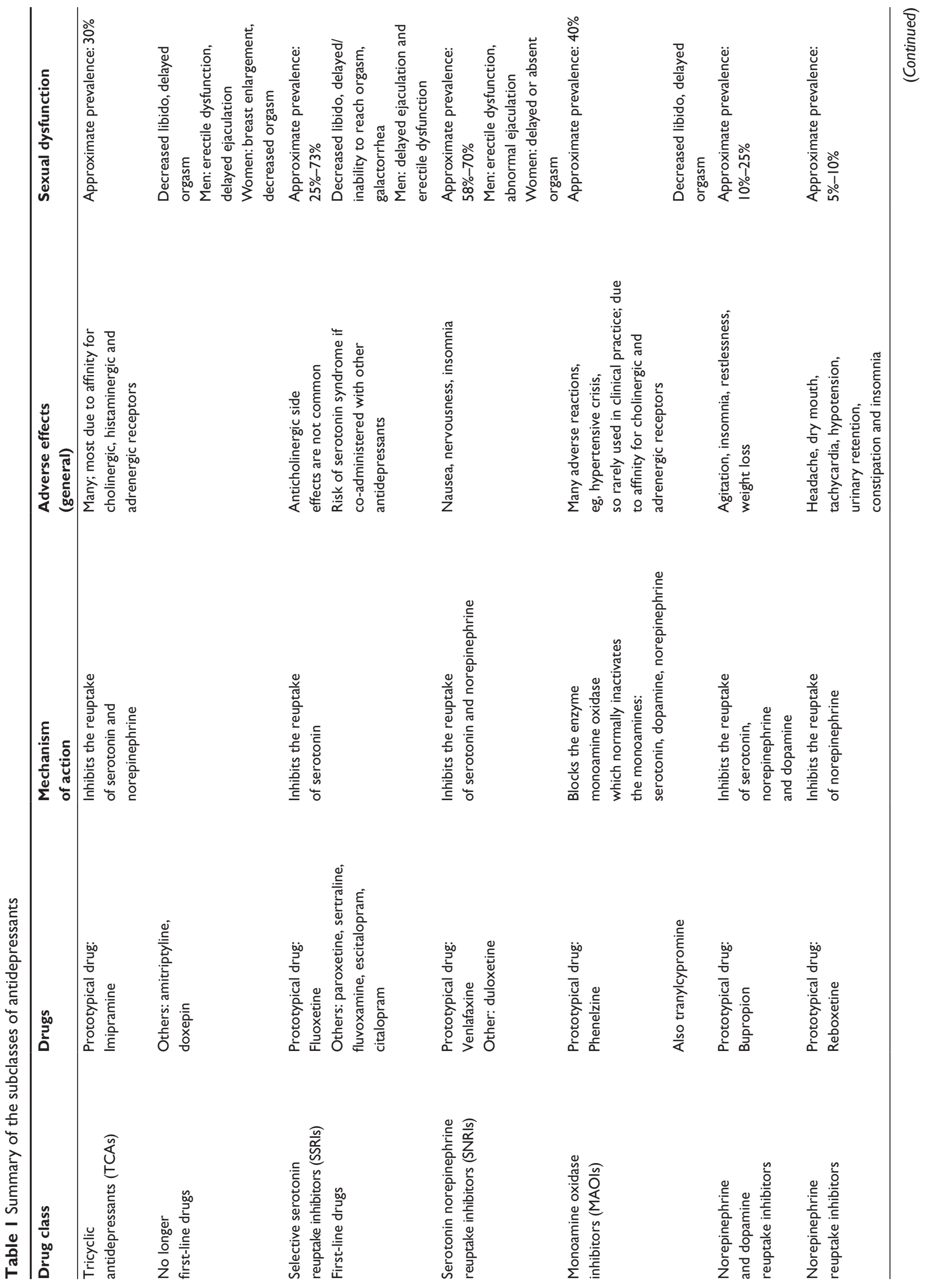


tion with sexual functioning was greater with nefazodone; $67 \%$ of men taking sertraline reported ejaculatory difficulties compared with $19 \%$ of the nefazodone-treated group. In women, nefazodone was superior to sertaline on measure of ease of achieving orgasm and satisfaction with orgasmic ability. Some years later, Ferguson et $\mathrm{al}^{17}$ in an 8 -week double-blind study, also compared nefazodone with sertraline, this time among 105 people who were experiencing sexual dysfunction attributable to sertraline. Clients were randomly assigned to either group following a 1-week wash out period and a subsequent 7-10-day placebo phase. Similar to the previous studies, sertaline-treated clients reported more drug-related sexual dysfunction. $76 \%$ of the sertaline-treated clients experienced reoccurrence of sexual dysfunction (ejaculatory or orgasmic difficulty) compared with $26 \%$ of the nefazodone-treated group. In this study, 5 of the sertaline-treated clients discontinued therapy because of sexual dysfunction.

A small number of double-blind comparative studies with placebo control have been conducted. Croft et $\mathrm{al}^{1}$ compared the effects of sustained-release bupropion, sertraline, and placebo on sexual function with 360 people with moderate to severe depression. Findings indicated that people treated with sertraline experienced significantly more sexual dysfunction throughout the duration of the study compared with those treated with bupropion SR or placebo. Orgasmic dysfunction occurred after only 1 week of treatment in sertaline-treated clients and continued throughout the 8 -week treatment. There were no significant differences in the occurrence of orgasmic dysfunction between bupropion SR and placebo at any time during the study. Coleman et a ${ }^{18}$ compared the sexual function effects of bupropone, fluoxetine, and placebo in 456 people. Again, decline in sexual functioning, sexual desire, and sexual arousal were more frequently associated with fluoxetine treatment than with bupropine or placebo. These findings support findings from other studies that suggest bupropion SR is relatively free of sexual side effects, ${ }^{11,19}$ and supports the contention that bupropion SR may be an appropriate antidepressant for clients concerned about sexual function.

Within the literature there are also a number of case study-anecdotal accounts of other sexual side effects, such as: priapism associated with paroxetine $;{ }^{20}$ painful ejaculation associated with venlafaxine, ${ }^{21}$ reboxetine, ${ }^{22}$ and tricyclics, ${ }^{23}$ loss of sensation in the vagina and nipples, ${ }^{24}$ penile anesthesia associated with fluoxetine ${ }^{25}$ and sertraline, ${ }^{26}$ and spontaneous ejaculation with reboxetine, an SNRI known for its lack 
of sexual side effects. ${ }^{27}$ In addition, decreased nocturnal erections have been reported with amitriptyline..$^{28}$

Over the years, several case reports have been published on a relationship between antidepressants and nonpuerperal lactation or galactorrhea in women. Egberts et al ${ }^{29}$ concluded from their analysis of reported drug reactions to the Netherlands Pharmacovigilance Foundation, between 1986 and 1996, that SSRIs and clomipramine were associated with approximately eight times higher risk of nonpuerperal lactation in women, when compared with women taking nonserotonergic antidepressants. Although rare, withdrawal syndromes that impact on sexuality and sexual function have also been described. In a recent article, Leiblum and Goldmeier $^{30}$ describe persistent genital arousal disorder in five women who attribute the onset of their sensations to either the usage or discontinuation of an SSRI. The women found the sensation distressing, with only brief relief from orgasm, and reported that their genital arousal was qualitatively different from sexual arousal that is preceded by sexual desire and/or subjective arousal.

There are very few studies that examine the impact of antidepressants on people without a mental health problem. Kowalski et al ${ }^{31}$ conducted a double-blind trial in a group of men without psychiatric diagnosis, to compare the impact of amitriptyline, mianserin, and placebo on nocturnal sexual arousal. Both amitriptyline and mianserin significantly decreased the amplitude and duration of nocturnal erections. Kennedy et $\mathrm{a}^{132}$ compared the effects of moclobemide and placebo on 60 healthy male and female adults and found no difference in the effects on sexual interest or sexual function in healthy volunteers. It needs to be remembered, however, that moclobemide is an antidepressant with the lowest incidence of reported sexual dysfunction in clients being treated for depression. ${ }^{12}$

Although the research provides firm evidence that antidepressant medication is associated with sexual dysfunction in both men and women, reaching any firm conclusion about the exact prevalence is difficult. Data on the prevalence of sexual dysfunction among the general population is scarce making it difficult to establish a 'normal' baseline..$^{33}$ In addition, there are very few large studies that explored the effects of antidepressants on adults without depression, or who used placebo controls. In their review of evidence of sexual dysfunction associated with antidepressants, Montgomery et $a l^{33}$ describe methodological problems such as absence of comparison groups, inconsistent definitions of sexual dysfunction, absence of baseline assessment of sexual functioning, and the use of various measures of sexual functioning as well as the questionable validity of the rating scales used. There is also a difficulty within the studies in separating sexual dysfunction resulting from depression and that resulting from the drugs - as depression itself is associated with decreased libido, decreased sexual activity, and decreased erectile and orgasmic excitement. ${ }^{34}$ Balon $^{4}$ highlights that most studies do not take into account other coexisting problems such as substance misuse, physical health problems, and other medications that may contribute to sexual dysfunction. The variation in rates between studies is also possibly due to the wide variety of measures used to measure sexual functioning, use of different samples, and recruitment strategies. However, a number of writers suggest that, in all probability, the difference in rates is due to substantial underreporting rather than under occurrence. ${ }^{8,11}$

\section{Differential effects of the various antidepressant classes and drugs}

In general, the mechanisms of action involve either the inhibition of breakdown of norepinephrine or blocking the reuptake of serotonin and norepinephrine at the presynaptic terminal, resulting in increased neurotransmitter availability at the synapse.

Sex is more than a physical act. It also includes emotional and psychological dimensions. The normal sex cycle consists of four successive phases: desire, arousal, orgasm, and resolution..$^{35}$ These phases are facilitated by the interplay of neurotransmitters, hormones, and peptides. Different classes of antidepressants impact on all phases of the sexual response cycle to varying degrees, and the details pertaining to each class of antidepressant are summarized in Table 1.

The challenge is to understand how antidepressants impact on normal sexual function. Because most antidepressants modulate serotonin concentration, it is generally thought that elevated serotonin levels diminish sexual function. ${ }^{37}$ Serotoninergic nerve terminals target dopamine and norepinephrine pathways in the brain and inhibit their activity, ${ }^{38}$ both of these neurotransmitters having a role in the desire and arousal phases of the sexual response cycle. $80 \%$ of serotonin is localized in the periphery, where when elevated, it directly reduces sensation in the anatomical structures of the reproductive system as well as diminishing erection, vaginal lubrication, ejaculation, and orgasm..$^{39}$ According to Nelson et al, ${ }^{40}$ the 5HT2 and 5HT3 receptor subtypes underlie serotoninergic-mediated sexual dysfunction. In addition, serotonin inhibits nitric oxide production, which normally has a role in relaxing the smooth muscle of the vasculature (including the vasculature of the reproductive 
structures), thus enabling vasodilation and allowing sufficient blood supply to the sexual organs during the sexual response cycle. $^{41}$

The autonomic nervous system regulates the mechanistic aspects of sexual function (eg, orgasm and ejaculation) and utilizes acetylcholine (parasympathetic and sympathetic systems) and norepinephrine (sympathetic system). Many antidepressants have some efficacy at cholinergic and alpha1-adrenergic receptors, thereby inhibiting the autonomic nervous system and consequently inhibiting normal sexual function. ${ }^{10}$

Long-term exposure may impact at the genetic level to effect functioning of the catecholaminergic and endocrine systems, ${ }^{42}$ such as antidepressant-associated changes to semen quality and DNA integrity. ${ }^{43,44}$

\section{The management of antidepressant-associated sexual dysfunction}

It is estimated that $30 \%$ of people treated for depression may be noncompliant with treatment; minimization of antidepressant-associated sexual dysfunction could be an important factor in successful treatment and health outcomes. ${ }^{18}$ The management of antidepressant-associated sexual dysfunction is complex. Balon ${ }^{4}$ suggests that "given the scarcity of evidence-based treatments the management of sexual dysfunction is still an art rather than a science" (p. 1506).

As stated earlier, the normal sexual response cycle consists of four successive phases: desire, arousal, orgasm, and resolution. ${ }^{35}$ The management of antidepressant-associated sexual dysfunction should endeavor to address sexual dysfunction equating to each stage of the sex cycle. However, this is not entirely possible as, as Jespersen ${ }^{45}$ suggests, poor overall sexual satisfaction is a common complaint of clients with antidepressant-associated sexual dysfunction.

Therefore, the first stage of effective management is a thorough assessment to ensure that the reported sexual dysfunction is indeed a consequence of antidepressant treatment. This will involve a re-evaluation of the depressive episode, including a physical and sexual health assessment. As Zajecka ${ }^{46}$ states, "the first step in management is to define the actual complaint and then attempt to determine the aetiology" (p. 35). This may not be as easy as it appears.

A thorough assessment will focus on:

- Eliminating confounding factors for sexual dysfunction, eg, age or alcohol/substance use
- Excluding a comorbid physical complaint, eg, side effects of drugs used to manage diabetes or hypertension may be a cause of sexual dysfunction. ${ }^{47}$ Higgins ${ }^{48}$ states that diabetes, atherosclerosis, cardiac disease, central and peripheral nervous system disease, and alcoholism can also contribute to sexual dysfunction.

- Excluding ongoing, or residual, symptoms of depression. Kennedy et $\mathrm{al}^{49}$ found in a sample of people with major depression (55 male and 79 female), over $40 \%$ of men and $50 \%$ of women reported decreased sexual interest prior to antidepressant treatment.

The main challenge faced by practitioners is managing antidepressant-associated sexual dysfunction without compromising the mental wellbeing of the client. This very fine balancing act may not be resolved adequately to everyone's liking. Noncompliance may constitute a big problem for practitioners as this will have a positive effect on antidepressant-associated sexual dysfunction. However, the obvious complication here is for relapse into the depressive state. Therefore, practitioners must be honest and open with the client in order to build trust, which can empower them to make better decisions about both their physical health and mental wellbeing.

There are various pharmacological and nonpharmacological ways of managing antidepressantinduced sexual dysfunction.

\section{Drug adaption}

In most cases, antidepressant regimes may be short term. Therefore, clients may opt to endure the effects of sexual dysfunction for a short period, until their treatment ends. Part of this may stem from a perception that their 'sex life' not being as bad with medication side effects as it was with their depression.

Once initiated, any medication requires a phase of adaption due to the potential unintended, or unforeseen, reactions. Drug adaption requires accommodation. Some adverse drug reactions, eg, nausea or blurred vision, recede as the client's body adapts to the antidepressant. Therefore, one course of management of antidepressant-associated sexual dysfunction is a 'wait and see' approach. Montejo et al ${ }^{12}$ suggest that spontaneous and partial remission of antidepressantassociated sexual dysfunction occurs in $10 \%$ of individuals treated with antidepressant agents. However, this still leaves a large proportion of individuals who will not spontaneously recover, even partially. Therefore this approach will not be suitable for all clients.

If antidepressant-associated sexual dysfunction emerges rapidly then this phase may be quickly passed over for one of the other possibilities. 


\section{Reduction in medication dosage}

The first point to consider relates to the client's medication regime. Practitioners should ask if the client is on their optimum dosage of antidepressant, ie, the optimum to manage the client's illness, not the optimum dosage that can be prescribed. This can give a vital space to proceeding with reducing medication dosage.

Antidepressant-associated sexual dysfunction may be a dose-related adverse event. Therefore reducing the dosage of the treatment to a minimum effective dose may be an option. However, this carries alternative risk to the client's mental health. While dose reduction is a management option, the practitioner must educate the client to be aware that reduction will not have an immediate effect on the antidepressantassociated sexual dysfunction. The rate at which the sexual dysfunction will recede will depend on the half-life of the particular antidepressant. If the client anticipates an immediate effect on dose reduction and it fails to materialize, the risk is that they abstain from their antidepressant regime.

\section{Switching medications}

Another strategy is switching antidepressants to one with a less risky side effect profile. This may include switching from an SSRI to non-SSRI antidepressant. This may give the potential benefits of continuing to manage the depressive illness while reducing the potential for sexual dysfunction.

In a systematic review of strategies for managing sexual dysfunction, Rudkin et $\mathrm{al}^{50}$ reported that switching from sertraline to nefazodone was significantly less likely to result in re-emergence of the sexual dysfunction and was not associated with any worsening depression. Zajecka ${ }^{46}$ suggests that nefazodone, bupropion, and possibly mirtazapine have minimal or no negative impact on sexual functioning. However, individual responses to this strategy may vary. Firstly, the sexual dysfunction may recede but the depressive illness reasserts itself. Secondly, the change of medication may result in other associated side effects which may be more debilitating as they are present throughout the client's day, not just when they want to have sex. Thirdly, the client who has experienced both the depression and the sexual dysfunction may feel that a 'little' depression is preferable to sexual dysfunction.

\section{Adjunct treatment}

As in most psychotropic medication regimes adjunct treatment, introducing another drug to counteract side-effects may be required. Clayton et a ${ }^{51}$ concluded from their double-blind comparison study involving 42 clients with SSRI-induced sexual dysfunction that bupropion SR was an effective antidote. In comparison with placebo, clients treated with bupropion SR showed a significantly greater improvement in desire and frequency of engaging in sexual activity. Labbate et $\mathrm{al}^{52}$ found that bupropion $75 \mathrm{mg}$ q.d. reversed SSRI induced sexual dysfunction. However, this was a small case study with a sample of six people ( 4 female and 2 male). Demyttenaere and Huygens ${ }^{22}$ describe the successful treatment of two clients with tamsulosin (alpha 1A-adrenoceptor antagonist), who had experienced antidepressant-induced painful ejaculation. Michelson et a ${ }^{153}$ concluded from their trial that neither buspirone nor amantadine was more effective than placebo in improving fluoxetineinduced sexual dysfunction in women.

There is evidence from systematic review of randomized, controlled trials into the management of antidepressantinduced sexual dysfunction that the addition of sildenafil (Viagra) will improve erectile dysfunction in men. ${ }^{50,54}$ The benefit to women has yet to be comprehensively proven. One randomized placebo controlled trial involving 98 women experiencing antidepressant induced sexual dysfunction concluded that sildenafil significantly reduced the adverse sexual effects, such as delayed orgasm responses and inadequate lubrication. ${ }^{55}$ However, the clinical benefit and risk have yet to be proven in large studies.

Alcantara ${ }^{56}$ states that drugs that act as 5-HT2-receptor agonists may cause sexual dysfunction by inhibiting the release of dopamine and noradrenaline. They suggest that 5-HT2 antagonism or strategies that increase noradrenergic or dopaminergic transmission may be useful in reversing sexual dysfunction.

Adjunct treatments should only be considered following a thorough physical assessment of the client and a medication review to address any contraindications with current psychotropic medications. Both sildenafil and bupropion have potential side effects. Sildenafil is associated with visual disturbances, palpitations, hypotension, and priapism, and bupropion may cause dry mouth, insomnia, gastrointestinal disturbances, and tremor. ${ }^{57}$ Individuals might perceive these side effects as more debilitating than sexual dysfunction. Therefore it is important that they have all the information on potential effects of adjunct treatments so that they can make informed decisions.

Conflicting evidence on the nature of herbal supplements such as ginkgo biloba as an adjunct treatment exists. In an open trial, ginkgo biloba was found to be effective in treating antidepressant induced sexual dysfunction generally having a positive effect on all four phases of the sexual response cycle: desire, excitement, orgasm, and resolution. ${ }^{58}$ The authors also note that women were more responsive to the sexually 
enhancing effects of ginkgo biloba than men. However, a group placebo controlled double blind trial of ginkgo biloba found no significant difference in sexual functioning in any phase, although the placebo group showed improved orgasm satisfaction. ${ }^{59}$ While its mode of action is not yet known, ${ }^{60}$ further trials of herbal supplements may be appropriate.

\section{Drug holiday}

A drug holiday is a high-risk treatment option where medication is omitted on the day of or prior to, anticipated sexual activity. While drug holidays are contentious and might not appeal to many practitioners, some evidence does exist which suggests stopping antidepressant medication on a temporary basis might be a potential strategy. In a trial of a drug holiday for SSRIinduced sexual dysfunction, Rothschild ${ }^{61}$ instructed 30 outpatients to discontinue their SSRIs after their Thursday morning dose and then restart at their previous dose on Sunday at 12:00 noon over four weekends. They found that clients taking sertraline and paroxetine reported a significant improvement in their sexual functioning, ie, improved libido and sexual satisfaction, but not by those taking fluoxetine. Furthermore, there were no statistically significant increases in mean Hamilton depression scores after discontinuation of the SSRIs.

Keltner et $\mathrm{al}^{41}$ suggests that drug holidays may impair therapeutic efficacy and lead to withdrawal symptoms. Drug holidays may be seen as an exercise in manipulating antidepressant half-life. Drugs such as fluoxetine, with a longer half-life, will need a longer drug holiday to ensure adequate excretion for sexual activity to occur. However, the longer the drug holiday the higher the risk of depressive symptoms recurring. Short half-life drugs, eg, venlafaxine, may be better with regards to facilitating sexual activity; however, again the risk of depressive symptoms reasserting themselves increases due to the short half life. Drug holidays also carry the risk of the client experiencing withdrawal symptoms associated with their particular medication. In this event such withdrawal symptoms may render the individual unable to engage in sexual activity.

A drug holiday is a precursor to sexual activity. Therefore the mechanization of scheduling sexual activity so that the drug holiday can be introduced may be another drawback of this approach. Timetabling is no substitute for romance that partners may appreciate as part of their sexual cycle. Setting deadlines like this may also increase 'performance' anxiety which might further compound the problem. The partner will also need to be educated about the condition if drug holidays are to be introduced as they may be able to give corroborative information regarding their effectiveness.

\section{Cognitive behavioral therapy}

Counseling therapies such as cognitive behavioral therapy (CBT) may be used in a biopsychosocial approach to sexual dysfunction. CBT focuses on current issues that are causing present problems. As such, it can help people change how they think in order to increase positive coping. CBT breaks problems down so that individuals can see the links between thoughts, feelings, and behavior.

While CBT is a recognized nonpharmacological intervention for a range of psychiatric disorders including depression, ${ }^{62}$ there is little evidence of effectiveness of CBT for antidepressant-associated sexual dysfunction. Indeed while CBT alone may not be wholly appropriate for managing the sexual dysfunction, it may be useful in managing negative feelings that may have a hugely negative impact on the individual's self esteem and self image. Feelings of sexual inadequacy may further compound any depressive illness and may put the client at risk of noncompliance. In CBT, clients can talk about the emotional impact of the sexual dysfunction and get psychological and emotional support, while still adhering to treatment regimes. Another key factor in CBT will be education of the client regarding their sexual dysfunction. This may help reduce catastrophic thinking and even prepare for possible future events should they arise.

A CBT action plan would seek to challenge these negative thoughts in order to enhance self image and self esteem. This approach requires both tact and expertise as the problem may be seen to be the medication not the sexual dysfunction. Part of this overall psycho-education should involve the partner who may be equally affected. Sex therapy or 'couples' counseling would be another alternative, which again would focus not on the core problem of sexual dysfunction but on how the couple can cope with its consequences. The unaffected partner will also need education so that they can be reassured that the sexual dysfunction is not related to a disinterest in them but as a result of medication.

The overall management of sexual dysfunction will involve pre- and post-test sexual dysfunction and depression surveys. This will test the efficacy of any intervention in reducing sexual dysfunction and how interventions affect the depressive illness. The conundrum for managing sexual dysfunction is what is more important in antidepressant treatment - the threshold for efficacious treatment of depression or managing the threshold of adverse drug reactions such as sexual dysfunction. This will evidentially need to be decided on a case by case basis. 


\section{Conclusion}

Depression is a common mental health problem for which a key intervention is antidepressant medication. Although there is extensive evidence that antidepressants, especially the SSRI group, cause sexual dysfunction in both men and women, estimating the exact prevalence is difficult. The sexual problems reported are extensive, ranging from decreased sexual desire, decreased sexual excitement, diminished or delayed orgasm, to erection or delayed ejaculation problems. In addition, there are a number of anecdotal accounts and case reports of sexual side effects, such as priapism, painful ejaculation, penile anesthesia, decreased nocturnal erections, and spontaneous ejaculation in men; and loss of sensation in the vagina and nipples, persistent genital arousal, and nonpuerperal lactation or galactorrhea in women.

Tackling the problem of antidepressant-induced sexual dysfunction is complex and requires partnership between research and practice. While some evidence regarding pharmacological management of antidepressant-associated sexual dysfunction exists, Taylor et $\mathrm{a}^{54}$ suggest that this is rather limited and insufficient to formulate a clinical guideline. The first step in managing antidepressant-induced sexual dysfunction is assessment. For many practitioners this may be challenging given the taboo that surrounds sex and sexual health. Taking a sexual history might be awkward for clinicians and clients alike. However as clinicians make this a routine part of their practice for this specific client group, they will enhance their skills and practice, transforming their awkwardness into expertise, which will ensure clients feel well attended to and able to discuss issues openly. Initial awkwardness will be a small price to pay for enhancing clinical practice and the quality of client care in this area. Waiting for clients to break the silence and raise their concerns may leave many clients isolated, confused, and distressed or fearful - not just of the drugs, but of engaging in intimate relationships. Good assessment will generate good information that will enhance effective clinical decision making.

Treating and managing antidepressant-induced sexual dysfunction requires a holistic approach as sufferers may be skeptical of pharmacological only remedies. There is evidence that bupropion and nefazodone, compared with SSRI group, are far less likely to cause sexual dysfunction, and that sildenafil will improve erectile dysfunction in men. However, nonpharmacological interventions such as sex therapy, CBT, and homeopathic remedies should be considered within practice and in further research.

\section{Disclosure}

The authors report no conflicts of interest in this work.

\section{References}

1. Croft HA, Settle E, Houser T, Batey S, Donahue R, Ascher J. A placebo-controlled comparison of antidepressant efficacy and effects on sexual function of sustained-release bupropion and sertraline. Clin Ther. 1999;21:643-658.

2. Clayton AH, Keller A, McGarvey EL. Burden of phase-specific sexual dysfunction with SSRIs. J Affect Disord. 2006;91:27-32.

3. Higgins A, Barker P, Begley CM. Iatrogenic sexual dysfunction and the protective withholding of information: in whose best interest? J Psychiatr Ment Health Nurs. 2006;13:437-446.

4. Balon R. SSRI-associated sexual dysfunction. Am J Psychiatry. 2006;163:1504-1509.

5. Higgins A, Barker P, Begley CM. 'Veiling sexualities': a grounded theory of mental health nurses responses to issues of sexuality. $J A d v$ Nurs. 2008;62:307-17.

6. Rothschild A. Sexual side effects of antidepressants. J Clin Psychiatry. 2000;61 Suppl 11:28-36.

7. Harrison WM, Rabkin JG, Ehrhardt AA, et al. Effects of antidepressant medication on sexual function: a controlled study. J Clin Psychopharmacol. 1986;6:144-149.

8. Kennedy SH, Eisfeld BS, Dickens SE, Bacchiochi JR, Bagby RM. Antidepressant-induced sexual dysfunction during treatment with moclobemide, paroxetine, sertraline, and venlafaxine. J Clin Psychiatry. 2000;61:276-281.

9. Ekselius L, von Knorring L. Effect on sexual function of long-term treatment with selective serotonin reuptake inhibitors in depressed clients treated in primary care. J Clin Psychopharmacol. 2001;21:154-160.

10. Montjo-Gonzales A, Llorce G, Izquierdo J, et al. SSRI - induced sexual dysfunction: fluoxetine, paraoxetine, sertaline and fluvoxamine in a prospective, multicenter, and descriptive clinical study of 344 patients. J Sex Marital Ther. 1997;23:176-187.

11. Modell J, Katholi C, Modell J, De-Palma R. Comparative sexual side effects of bupropion, fuloxetine, paroxetine and sertraline. Clin Pharmacol Ther. 1997;61:476-487.

12. Montejo A, Llorca G, Izquierdo J, Rico-Villademoros F. Incidence of sexual dysfunction associated with antidepressant agents: a prospective multicenter study of 1022 outpatients. Spanish Working Group for the Study of Psychotropic-Related Sexual Dysfunction. J Clin Psychiatry. 2001;62 Suppl 3:10-21.

13. Clayton A, Pradko J, Croft H, et al. Prevalence of sexual dysfunction among newer antidepressants. J Clin Psychiatry. 2002; 63(4):357-366.

14. Kavoussi R, Segraves R, Hughes A, Ascher J, Johnston J. Double-blind comparison of bupropion sustained release and sertraline in depressed outpatients. J Clin Psychiatry. 1997;58:532-537.

15. Segraves R, Kavoussi R, Hughes A, et al. Evaluation of sexual functioning in depressed outpatients: a double-blind comparison of sustainedrelease bupropion and sertraline treatment. J Clin Psychopharmacol. 2000;20:122-128.

16. Feiger A, Kiev A, Shrivastava R, Wisselink P, Wilcox C. Nefazodone versus sertaline in outpatients with major depression: focus on efficacy, tolerability, and effects on sexual function and satisfaction. $J$ Clin Psychiatry. 1996;57 Suppl 2:53-62.

17. Ferguson J, Shrivastava, R, Stahl S, et al. Reemergence of sexual dysfunction in patients with major depressive disorder: double-blind comparison of nefazodone and sertraline. J Clin Psychiatry. 2001;62: 24-29.

18. Coleman C, King B, Bolden-Watson C, Book M, Segraves R, Richard N. A placebo-controlled comparison of the effects on sexual functioning of bupropion sustained release and fluoxetine. Clin Ther. 2001;23:1040-1058.

19. Gardner E, Johnston J. Bupropion: an antidepressant without sexual pathology. J Clin Psychopharmacol. 1985;5:24-29.

20. Ahmad S. Paroxetine induced priapism. Arch Intern Med. 1995; 155:645.

21. Michael A. Venlafaxine-induced painful ejaculation. Br J Psychiatry. 2000;177:282-283. 
22. Demyttenaere K, Huygens R. Painful ejaculation and urinary hesitancy in association with antidepressant therapy: relief with tamsulosin. Eur Neuropsychopharmacol. 2002;12:337-341.

23. Aizenberg D, Zemishlany Z, Hermesh H, Karp L, Weizman A. Painful ejaculation associated with antidepressants in four patients. J Clin Psychiatry. 1991;52:461-463.

24. Michael A, Mayer C. Fluoxetine-induced anaesthesia of vagina and nipples. Br J Psychiatry. 2000;176:299.

25. Neill JR. Penile anaesthesia associated with fluoxetine use. Am J Psychiatry. 1991;148(11):1603.

26. Bolton J, Sareen J, Reiss J. Genetial anaesthesia persistign six years after sertraline discontinuation. J Sex Marital Ther. 2006;32(4):327-330.

27. O’Flynn R, Michael A. Reboxetine-induced spontaneous ejaculation. Br J Psychiatry. 2000;177:567-568.

28. Kowalski A, Stanley RO, Dennerstein L, Burrows G, Maguire KP. The sexual side-effects of antidepressant medication: a double-blind comparison of two antidepressants in a non-psychiatric population. Br J Psychiatry. 1985 Oct;147:413-418.

29. Egberts AC, Meyboom RH, De Koning FH, Bakker A, Leufkens HG. Non-puerperal lactation associated with antidepressant drug use. $\mathrm{Br} J$ Clin Pharmacol. 1997;44(3):277-281.

30. Leiblum S, Goldmeier D. Persistent genital arousal disorder in women: case reports of association with anti-depressant usage and withdrawal. J Sex Marital Ther. 2008;34:150-159.

31. Kowalski A, Stanley R, Dennerstein L, Burrows G, Maguire K. The sexual side-effects of antidepressant medication: a double blind comparison of two antidepressants in non-psychiatric population. $\mathrm{Br} J$ Psychiatry. 1985;147:413-418.

32. Kennedy SH, Ralevski E, Davis C, Neitzert C. The effects of moclobemide on sexual desire and function in health volunteers. Eur Neuropsychopharmacol. 1996;6:177-181.

33. Montgomery SA, Baldwin DS, Riley A. Antidepressant medications: a review of the evidence for drug-induced sexual dysfunction. J Affect Disord. 2002;69(1-3):119-140.

34. Pesce V, Seidman SN, Rosse SP. Depression, antidepressants and sexual function in men. Sexuality Relationship Ther. 2002;17:281-287.

35. Outhoff K. CPD Article: antidepressant-induced sexual dysfunction. South African Family Practice. 2009;51:298-302.

36. Taylor D, Paton C, Kerwin R, editors. The Maudsley Prescribing Guidelines. UK: Informa Healthcare; 2007.

37. Rosen R, Lane R, Menza M. Effects of SSRIs on sexual function: a critical review. J Clin Psychopharmacol. 1999;19(1):67-85.

38. Stahl S. Basic psychopharmacology of antidepressants, Part 1: Antidepressants have seven distinct mechanisms of action. J Clin Psychiatry. 1998;59 Suppl 4:5-14.

39. Frohlich P, Meston C. Evidence that serotonin affects female sexual functioning via peripheral mechanisms. Physiol Behav. 2000;71(3-4):383-393.

40. Nelson E, Shah V, Welge J, Keck PJ. A placebo-controlled, crossover trial of granisetron in SRI-induced sexual dysfunction. J Clin Psychiatry. 2001;62(6):469-473.

41. Keltner NL, McAfee KM, Taylor CL. Mechanisms and treatments of SSRI-induced sexual dysfunction. Perspect Psychiatr Care. 2002; 38(3):111-116

42. Yamada M, Yamada M, Higuchi T. Antidepressant-elicited changes in gene expression: remodeling of neuronal circuits as a new hypothesis for drug efficacy. Prog Neuropsychopharmacol Biol Psychiatry. 2005(29): 999-1009.

Drug, Healthcare and Patient Safety

\section{Publish your work in this journal}

Drug, Healthcare and Patient Safety is an international, peer-reviewed open-access journal exploring patient safety issues in the healthcare continuum from diagnostic and screening interventions through to treatment, drug therapy and surgery. The journal is characterized by the rapid reporting of reviews, original research, clinical, epidemiological and
43. Safarinejad M. Sperm DNA damage and semen quality impairment after treatment with selective serotonin reuptake inhibitors detected using semen analysis and sperm chromatin structure assay. J Urol. 2008;180(2124-2128).

44. Tanrikut C, Schlegel P. Antidepressant-associated changes in semen parameters. Urology. 2007;69:185.e5-e7.

45. Jespersen S. Antidepressant induced sexual dysfunction. Part 2: assessment and Management. South African Psychiatry Review. 2006(9):79-83.

46. Zajecka J. Strategies for the treatment of antidepressant-related sexual dysfunction. J Clin Psychiatry. 2001;62 Suppl 3:35-43.

47. Watson J, Davies T. ABC of mental health psycho-sexual problems. BMJ. 1997;15(7102):239-242.

48. Higgins A. The impact of psychotropic medication on sexuality: literature review. Br J Nurs. 2007;16(9):545-550.

49. Kennedy SH, Dickens SE, Eisfield B, Bagby M. Sexual dysfunction before antidepressant therapy in major depression. J Affect Disord. 1999;56(2-3):201-208.

50. Rudkin L, Taylor M, Hawton K. Strategies for managing sexual dysfunction induced by antidepressant medication Cochrane Database of Systematic reviews 2004; Issue 4 (Art, No.: CD003382. DOI:10.1002/14651858. CD003382.pub2.).

51. Clayton A, Warnock J, Kornstein S, Pinkerton R, Sheldon-Keller A, McGarvey E. A placebo-controlled trial of bupropion SR as an antidote for selective serotonin reuptake inhibitor-induced sexual dysfunction. J Clin Psychiatry. 2004;65:62-67.

52. Labbate L, Grimes J, Hines A, Pollack M. Bupropion treatment of serotonin reuptake antidepressant-associated sexual dysfunction. Ann Clin Psychiatry. 1997;9(4):241-245.

53. Michelson D, Bancroft J, Targum S, Kim Y, Tepner R. Female sexual dysfunction associated with antidepressant administration: a randomized, placebo-controlled study of pharmacologic intervention. Am J Psychiatry. 2000;157:239-243.

54. Taylor M, Rudkin L, Hawton K. Strategies for managing antidepressantinduced sexual dysfunction: systematic review of randomized controlled trials. J Affect Disord. 2005;88:241-254.

55. Nurnberg H, Hensley P, Heiman J, Crofy H, Debattista C, Paine S. Sildenafil treatment of women with antidepressant-associated sexual dysfunction. A randomized controlled trial. JAMA. 2008;300:395-404.

56. Alcantara A. A possible dopaminergic mechanism in the serotonergic antidepressant-induced sexual dysfunctions. J Sex Marital Ther. 1999;25:125-129.

57. British National Formulary. British National Formulary (BNF) Number 53: BMJ Publishing Group UK; 2007.

58. Cohen AJ, Bartlik. Ginkgo biloba for antidepressant-induced sexual dysfunction. J Marital Sex Ther. 1998;24:139-143.

59. Kang BJ, Lee SJ, Kim MD, Cho MJ. A placebo-controlled, double-blind trial of ginkgo biloba for antidepressant-induced sexual dysfunction. Human Psychopharmacol. 2002;17:279-284.

60. Labbate LA, Croft HA, Oleshansky MA. Antidepressant-related erectile dysfunction: management via avoidance, switching antidepressants, antidotes, and adaptation. J Clin Psychiatry. 2003;64 Suppl 10:11-19.

61. RothschildA. Selective serotonin reuptake inhibitor-induced sexual dysfunction: efficacy of a drug holiday. Am J Psychiatry. 1995;1(152):1514-1516.

62. Butler C, Chapman J, Forman E, Beck A. The empirical status of cognitive-behavioural therapy: a review of meta-analyses. Clin Psychol Rev. 2006;26:17-31.

post-marketing surveillance studies, risk management, health literacy and educational programs across all areas of healthcare delivery. The manuscript management system is completely online and includes a very quick and fair peer-review system. Visit http://www.dovepress.com/ testimonials.php to read real quotes from published authors. 